ANO 10 • NÚMERO $19 \cdot 2$ 2os 2013 • ORGANICOM A COMUNICAÇÃO INTERNA E A CONSTRUÇÃO DA CULTURA ORGANIZACIONAL EM EQUIPES ESPORTIVAS VENCEDORAS: O CASO DO FC BARCELONA

\title{
A comunicação interna e a construção da cultura organi- zacional em equipes esportivas vencedoras: o caso do FC Barcelona
}

Internal communication and the building of organizational culture in winning sports teams: FC Barcelona case study

La comunicación interna y la construcción de la cultura organizacional en equipos deportivos vencedores: el caso del FC Barcelona

Ary José Rocco Junior

- Doutor em Comunicação e Semiótica pela Pontifícia Universidade Católica de São Paulo (PUC-SP)

- Mestre em Administração e Planejamento pela PUC-SP

- Graduado em Administração Pública pela Fundação Getúlio Vargas (FGV-SP) e em Jornalismo pela Faculdade Cásper Líbero (Facásper)

- Professor da Escola de Educação Física e Esporte da Universidade de São Paulo (Eefe-USP) e do Mestrado Profissional em Administração - Gestão do Esporte da Universidade Nove de Julho (Uninove)

- Coordenador do grupo de pesquisa "Comunicação e esporte", da Sociedade Brasileira de Estudos Interdisciplinares em Comunicação (intercom)

- Diretor da Asociación Latinoamericana de Gerencia Deportiva (Algede)

- Tem experiência nas áreas de comunicação e gestão do esporte

- E-mail:aryrocco@usp.br 


\section{Resumo}

0 papel das organizações esportivas, no Brasil, adquiriu especial importância nos últimos anos. A relevância de seu planejamentoestratégicofezcresceranecessidadedoinvestimentoemestratégias decomunicaçãoatéentãonegligenciadas. 0 aspecto mais sensível dessas estratégias foi sentido apenas na comunicação mercadológica. A construção de uma cultura organizacional que permita o aproveitamento de uma identidade que agregue todos os stakeholders dessas instituições ainda é desprezada. 0 objetivo deste artigo é analisar, por meio do exemplo do FC Barcelona, o papel da comunicação interna na construção de um modelo de cultura organizacional que apresente resultados esportivos e mercadológicos.

PALAVRAS-CHAVE: CULTURA ORGANIZACIONAL・MARKETING ESPORTIVO • CLUBES ESPORTIVOS • ESPORTE DE ALTO RENDIMENTO • FC BARCELONA.

\section{Abstract}

The role of sports organizations in Brazil gained special importance in recent years. The relevance of the strategic planning of these entities has increased the need for investment in communication strategies hitherto neglected. The most sensitive aspect of these strategies was noticed only in marketing communication. The building of an organizational culture that enables leveraging an identity that aggregates all stakeholders of these institutions is still neglected. The purpose of this article is to analyze, taking the example of FC Barcelona, the role of internal communication in building a model of organizational culture that delivers sports and market results.

KEYWORDS: ORGANIZATIONAL CULTURE・SPORTS MARKETING・SPORTS CLUBS・ELITE SPORT・FC BARCELONA.

\section{Resumen}

El papel de las organizaciones deportivas en el Brasil, adquirió especial importancia en los últimos años. La relevancia de su planificación estratégica incrementó la necesidad de invertir en estrategias de comunicación hasta ahora olvidadas. El aspecto más sensible de estas estrategias se sintió solo en la comunicación mercadológica. La construcción de una cultura organizacional que permite el aprovechamiento de una identidad que agregue a todos los stakeholders de estas instituciones todavía es desdeñado. El objetivo de este trabajo es analizar, a través del ejemplo del FC Barcelona, el papel de la comunicación interna en la construcción de un modelo de cultura organizacional que presente resultados deportivos y mercadológicos.

PALABRAS CLAVES: CULTURA ORGANIZACIONAL・MARKETING DEPORTIVO • CLUBES DEPORTIVOS • DEPORTE DE ALTO RENDIMIENTO • FC BARCELONA. 
esde o seu surgimento até meados da década de 1990, a prática do futebol apresentava, em todo o mundo, profundas relações com aspectos culturais ligados às identidades nacionais ou à forma de ser de uma determinada nação ou região do Planeta. 0 modus de praticar o futebol funcionava, e em alguns casos ainda funciona, como marcante elemento de identificação de um povo ou país.

A partir da década de 1990, com o aprofundamento da globalização, o desenvolvimento tecnológico e a unificação dos mercados, os principais clubes de futebol do mundo transformaram-se em verdadeiras empresas multinacionais. Suas marcas passaram a ser trabalhadas globalmente e as receitas financeiras oriundas dos sistemas midiáticos cresceram de forma exponencial. Todos esses fatores, aliados ao desenvolvimento da tecnologia, passaram a demandar, por parte dessas agremiações, um sistema de gestão extremamente profissional.

A cultura da prática do esporte, antes associada a limites e fronteiras nacionais, passou a ter uma dimensão global. A base do esporte, até então alicerçada nas seleções nacionais, começou a ser determinada pelo desenvolvimento e crescimento dos principais clubes do mundo. 0 futebol, que era um produto simbolicamente do Estado, passou rapidamente, no imaginário dos seus adeptos e profissionais, a ser um produto regido por leis e regulamentos do mercado global. 0 desenvolvimento das estratégias de marketing esportivo, como a comunicação mercadológica de produtos e eventos esportivos, é fruto desse processo.

Com isso, a cultura das diferentes nacionalidades, que até então norteava a prática do esporte, começou a ser moldada, mesmo que de forma inconsciente, dentro de uma estrutura empresarial. Os principais clubes do mundo, formados por atletas de diversas nacionalidades, perceberam que o desenvolvimento de uma cultura própria, com a criação de uma identidade calcada em valores próprios, em geral redundava em excelentes resultados nas competições esportivas.

Exemplo mais marcante desse processo é o FC Barcelona, da Espanha. Identificando-se com a região onde se localiza, a Catalunha, o clube passou a catalisar, mediante um processo empresarial de aculturamento de seus atletas, uma série de valores próprios que identificam a agremiação em todo o mundo. 0 slogan "mais que um clube"1 traduz esse sentimento presente na formação de cada um dos atletas que compõem a equipe principal do clube, gerenciada estrategicamente pela agremiação.

Como resultado dessa política de construção da cultura organizacional estruturada, o clube, além da identificação provocada em seus adeptos, que rendeu um excelente posicionamento econômico-financeiro, obteve brilhante tesportiva nos últimos anos, com a conquista de diversas competições na Espanha, dois títulos da Liga dos Campeões da Europa e um troféu do Campeonato Mundial de Clubes, promovido pela Fifa.

0 presente artigo tem como objetivo analisar, por meio do caso do FC Barcelona, o papel da comunicação interna para a construção estratégica da cultura organizacional, com excelentes reflexos na gestão da equipe catalã. 0 equilíbrio entre os excelentes resultados econômico, financeiro e desportivo é o principal reflexo desse processo.

1 "Més que un club", no idioma catalão. 


\section{O FUTEBOL E A IDENTIDADE NACIONAL}

Thomas Stearns Eliot (1988, p. 33) afirma que "a cultura do individuo depende da cultura de um grupo ou classe" e que "a cultura do grupo ou classe depende da cultura da sociedade a que pertence este grupo ou classe". A educação, ainda segundo Eliot (1988, p. 34), funciona como o elemento propagador da cultura. Cultura que se compõe de vários elementos e, no entender do autor, "vai da habilidade rudimentar e do conhecimento à interpretação do universo e do homem pela qual vive a comunidade".

O futebol é, hoje, um dos aspectos da cultura que mais interfere na vida social das pessoas e na formação da própria cultura de um país. A difusão do esporte pelo mundo possibilitou que diferentes culturas e nações construíssem formas particulares de identidade por meio de sua interpretação e forma de praticar o esporte mais popular do Planeta.

O Brasil, por exemplo, é reconhecido em todo o mundo como o "país do futebol". Tal reconhecimento ocorre, primordialmente, por causa dos excelentes resultados obtidos pelas seleções brasileiras de futebol nas copas do mundo de 1958, 1962, 19770, 1994 e 2002. Além do sucesso representado por essas conquistas, a forma de os brasileiros praticarem a modalidade futebol é admirada mundialmente pela habilidade de seus jogadores e pela beleza plástica com que suas equipes praticam o esporte.

Na Itália a prática do futebol é caracterizada historicamente pela filosofia do catenaccio, ou pela retranca, como dizemos no Brasil. Catenaccio significa literalmente, "porta trancada". É um sistema tático considerado vencedor pelos italianos, desde a década de 1960, quando a Internazionale de Milão, dirigida por Helenio Herrera, foi duas vezes campeã europeia de clubes utilizando esse sistema. 0 catenaccio é caracterizado por uma defesa forte, sólida e consistente, com destaque para o papel do líbero, atleta encarregado de "trancar" a defesa no caso de um dos seus companheiros falharem. Defender bem e não dar espaço para o adversário criar oportunidades de gol é o objetivo principal do modelo. Foi assim, utilizando esse sistema, que os italianos conquistaram a Copa do Mundo de 1982, na Espanha, derrotando o favorito e mágico Brasil, de Telê Santana; e, também, a Copa do Mundo de 2006, na Alemanha, com destaque para o líbero Fábio Cannavaro.

O sistema de jogo baseado no catenaccio valoriza alguns sentimentos presentes na cultura italiana. A questão da valorização do modelo de defesa alicerçado na proteção de sua meta remonta à história daquele país e, em especial, ao seu processo de reunificação. Foi durante esse processo que surgiram algumas "sociedades secretas" destinadas a proteger a nação italiana de um esfacelamento. A valorização desses elementos dá ao catenaccio profunda identificação com a forma e o hábito de ser do italiano.

A Alemanha, em sua forma de praticar o futebol, tem parte de seu sucesso no esporte atribuído à disciplina tática de seus jogadores. 0 jogar coletivamente, o conhecimento que cada atleta tem de seu papel no campo de jogo, o cumprimento fiel de suas funções no gramado, tudo isso sempre caracterizou e marcou o futebol praticado pelos germânicos. Tais valores, presentes na prática do esporte, são características profundas da sociedade alemã e, no futebol, permitiu ao país conquistar as copas de 1954, 1974 e 1990.

Outro país que marcou o futebol, em sua história e seu desenvolvimento, foi a Holanda. Na Copa do Mundo de 1974, os holandeses provocaram aquilo que ficou conhecido como uma verdadeira "revolução" na forma de praticar o esporte. Treinada por Rinus Michels e contando com uma geração de atletas talentosa e inteligente, com destaque para Cruyff 
e Neeskens, a chamada "laranja mecânica" marcou o esporte com uma nova forma de jogar, com constantes trocas de posições entre os jogadores, modificando os conceitos táticos do esporte até então. 0 novo estilo de jogo dos holandeses é conhecido, até hoje, como "futebol total". Tendo como base os clubes Ajax, de Amsterdã, e Feyenoord, de Roterdã², a forma de jogar da seleção holandesa daquela época é relacionada a padrões e hábitos culturais dos holandeses, como sua conhecida liberalidade e aceitação de costumes, em geral, não aceitos em outros países. A "suposta" liberalidade cultural serve como base conceitual para a constante movimentação dos atletas em campo, sem guardar posição fixa. 0 sucesso do esquema tático revolucionário holandês só foi possível graças à perfeição com que os jogadores - que tinham grande qualidade e sabiam atuar em qualquer posição - efetivavam os passes. Essa perfeição casa, de forma profunda, com a formação cultural do povo holandês.

No futebol, todos os exemplos mencionados acima - Brasil, Itália, Alemanha e Holanda - mostram que a forma de praticar o esporte reflete, em sua essência, os valores culturais de uma determinada sociedade. 0 aproveitamento desses valores culturais, fundamentais e presentes na formação natural do atleta em seu desenvolvimento como indivíduo, quando aproveitados adequadamente na prática esportiva, são refletidos na performance esportiva de suas equipes.

Tal fenômeno despertou, por muitas décadas, o interesse dos diversos governantes de várias nações do mundo para 0 potencial do esporte como elemento fortalecedor de nacionalidades. Por outro lado, com a queda do Muro de Berlim, aliada à globalização, o futebol deixou de interessar apenas aos estados e passou a ser alvo de empresas multinacionais que buscam, no seu íntimo, um único objetivo: a lucratividade dos seus negócios.

Estamos assistindo, assim, a uma passagem, mediada pelos grandes conglomerados multinacionais de comunicação e mídia, do futebol profissional internacional da esfera pública para a ordem capitalista de mercado. De elemento de afirmação de nacionalidades, o futebol passou a ser artífice do consumo, produto de venda para empresas e agremiações esportivas. Em outras palavras, estamos presenciando a transformação do futebol profissional internacional de produto da propaganda estatal em produto regido pelas leis do mercado capitalista.

\section{O FUTEBOL, A LÓGICA DE MERCADO, A COMUNICAÇÃO INTERNA E A CULTURA ORGANIZACIONAL}

A difusão do futebol de um lado a outro do mundo possibilitou que diferentes culturas e nações construíssem, como já mencionado, formas particulares de identidade por meio de sua interpretação e forma de jogar. Essa diversidade está sendo cada vez mais enfraquecida pela relação recíproca das forças econômicas e culturais, que estão transformando o futebol em um jogo cada vez mais incluído em um mercado global.

Richard Giulianotti (1999, p. 9), sociólogo e pesquisador do esporte, afirma que o futebol, até chegar a ser o que é hoje, passou "por estágios específicos, que podem ser caracterizados como 'tradicional', 'moderno' e 'pós-moderno".

Quando discuto o 'tradicional' estou falando sobre o 'pré-moderno', onde vestígios da era pré-industrial ou pré-capitalista são ainda muito influentes. (...) A 'modernidade' está relacionada à rápida urbanização e ao crescimento demográfico e político da classe trabalhadora. Estabelece-se uma divisão entre espaços masculinos (público, produtivo) e espaços femininos (privado, reprodutivo). (...) 0 crescimento dos meios de comunicação de massa, as melhorias de infraestrutura e a criação de programas de bem-estar

2 Os clubes holandeses dominaram o cenário europeu no início da década de 1970. O Feyenoord foi o campeão da antiga Copa dos Clubes Campeões da Europa, antigo nome da Liga dos Campeões, em 1970. 0 Ajax conquistou a mesma competição em 1971, 1972 e 1973. 
social também servem para suscitar sentimentos unitários de identidade nacional. (...) Em matéria de lazer e de recreação, a divisão entre burguesia e classes trabalhadoras é reproduzida por meio de uma diferenciação entre alta cultura ('legitimada') e baixa cultura ('popular'). (...) A 'pós-modernidade' é marcada pela dimensão crítica ou pela rejeição real da modernidade e de suas propriedades definidas. (...) As identidades sociais e culturais tornam-se cada vez mais fluidas e 'neotribais' em suas tendências de lazer. (...) A globalização dos povos, da tecnologia e da cultura dá origem a uma cultura híbrida e uma dependência econômica das nações em relação aos mercados internacionais.

Assim, podemos entender que o futebol profissional internacional está, atualmente, em sua fase pós-moderna. Nela, como diz Giulianotti, "as identidades sociais e culturais tornam-se mais fluidas e 'neotribais` em suas tendências de lazer". 0 sociólogo britânico também afirma que "a globalização dos povos, da tecnologia e da cultura dá origem a uma cultura híbrida e uma dependência econômica das nações em relação aos mercados internacionais".

A partir do final da Guerra Fria, com a queda do Muro de Berlim, estruturas políticas que sustentavam o futebol na esfera pública começam a se dissipar. Com isso, o esporte passa a viver um novo momento no qual o mercado global começa a dirigir seus tentáculos em direção ao apelo mercadológico no universo esportivo. "O processo que começamos a descrever como globalização pode ser resumido como a passagem das identidades modernas a outras que poderíamos chamar, embora o termo seja cada vez mais incômodo, de pós-modernas" (García-Canclini, 2001, p. 59).

Dentro desse contexto, merece destaque a crescente participação de empresas, clubes esportivos, seus patrocinadores, jornalistas e torcedores de futebol na construção de marcas cada vez mais fortes, relacionadas ao universo do esporte. Um grande número de empresas começou a enxergar nesse universo uma excelente perspectiva de negócio, colocando o evento esportivo como um dos principais vértices da indústria do entretenimento e, consequentemente, do consumo.

Para que a relação esporte-empresa funcione adequadamente, com a correta gestão das marcas e seu apropriado relacionamento com o evento esportivo, é necessária a construção de estratégias adequadas de comunicação que permitam, de forma concreta, a identificação plena de uma marca associada ao esporte. A implantação e o desenvolvimento de uma cultura organizacional aplicada a equipes esportivas é uma das estratégias mais adequadas para essa finalidade. No esporte, como afirmam Melissa J. Morgan e Jane Summers (2008, p. 45),

o produto é o jogo propriamente dito, mas há também alguns componentes intangíveis que precisam ser considerados. Os elementos tangíveis do produto esportivo são os praticantes de determinado esporte, o tipo de competição ou jogo praticado, as decisões de merchandising (camisetas, bonés, equipamentos etc.) e os locais dos jogos. Os elementos intangíveis são as impressões, experiências, emoções e interpretações demonstradas pelas pessoas em relação ao esporte, sejam elas participantes ou não.

0 valor ou beneficio percebido do produto esportivo é uma combinação de elementos tangíveis e intangíveis que são interpretados das mais variadas formas pelos consumidores do esporte. Nas suas decisões de consumo, os consumidores esportivos levam em consideração as demandas concorrentes por seu valor de troca, como dinheiro, tempo, atitude e posse. A dificuldade, para o profissional de comunicação do esporte, reside em avaliar quando o benefício do produto esportivo é tangível e quando é intangível. Ir a um jogo, por exemplo, é intangível, visto que a experiência de assistir ao esporte será algo de valor difícil de ser mensurado.

As características do produto esportivo fizeram crescer a importância da cultura organizacional. Com o apoio da mídia, um processo de gestão bem estruturado, que implante, desenvolva, comunique e deixe transparecer essa cultura para todos os stakeholders de uma agremiação esportiva, certamente trará benefícios econômicos, financeiros e esportivos para o clube que a implantar. 
A cultura organizacional encontra, então, no esporte contemporâneo, território profícuo para desempenhar seu papel com plenitude. 0 caráter intangível do produto esportivo, quando bem trabalhado pelos profissionais de comunicação, permite a construção de forte apelo institucional para a consolidação de uma cultura sólida para entidades esportivas.

No atual estágio de desenvolvimento do futebol, as principais agremiações esportivas do mundo, em especial da Europa, são comparadas às grandes organizações multinacionais. A modernização da gestão é, assim, vista como uma necessidade imediata para seu crescimento e desenvolvimento.

Um aspecto geralmente negligenciado pelos clubes esportivos é a construção ou valorização de uma cultura organizacional que possa identificar a agremiação com seus jogadores, colaboradores e torcedores, criando uma identidade clara e definida. Uma equipe esportiva, por exemplo, é composta por atletas que são indivíduos com características diversas, vindos dos mais diferentes países e culturas, que se unem para atuar dentro de um mesmo sistema sociocultural na busca de objetivos determinados, em geral, a conquista de títulos ou uma boa performance em uma determinada competição. Essa união provoca um compartilhamento de crenças, valores, hábitos, entre outros fatores, que irão orientar suas ações dentro de um contexto preexistente, definindo assim as suas identidades.

Para Jean-Pierre Dupuis (1996), são os indivíduos que, por meio de suas ações, contribuem para a construção de uma organização e sua identidade. Entretanto, os indivíduos agem sempre dentro de contextos que lhes são preexistentes e orientam o sentido de suas ações. Durante muito tempo, a construção do contexto estava baseada na territorialidade e transitava em torno de uma cultura nacional. Com a globalização, os vetores tempo e distância foram alterados em sua essência. 0 desenvolvimento das equipes de futebol transnacionais, formadas por indivíduos oriundos das mais diversas nacionalidades, passou a demandar um aculturamento dos atletas em torno de valores e de uma identidade comum.

Em outras palavras, a construção de uma cultura organizacional envolve a criação de um universo simbólico que possibilita aos membros integrantes de um grupo uma forma consensual de apreender a realidade, integrando os significados e viabilizando a comunicação. Para que isso possa acontecer, de forma concreta e natural, é necessário o desenvolvimento de corretas estratégias de comunicação interna. Como bem define Margarida Kunsch (2002, p. 154), a comunicação interna

seria um setor planejado, com objetivos bem definidos, para viabilizar toda a interação possível entre a organização e seus empregados, usando ferramentas de comunicação institucional e até de comunicação mercadológica (para 0 caso do endomarketing ou marketing interno). Portanto, a comunicação interna corre paralelamente com a circulação normal da comunicação que perpassa todos os setores da organização, permitindo seu pleno funcionamento. (...) Será pensada, planejada e avaliada de forma constante, não ocorrendo simplesmente de forma fortuita.

A comunicação interna permite, quando planejada de forma estratégica, que a realidade da instituição seja constituída por uma série de objetivos designados antes pela organização e depois pelos indivíduos que a compõem. Com isso, o colaborador percebe que existe correspondência entre os significados por ele atribuídos ao objeto e os significados atribuídos pelos outros. É o compartilhar de um senso comum sobre a realidade.

Ao definir padrões de comportamento com o objetivo de conservar a estabilidade e o equilíbrio do grupo, justifica-se a importância crescente conferida à comunicação interna e, consequentemente, à cultura organizacional. Um importante aspecto para a sobrevivência de um indivíduo é a necessidade de construção de uma identidade, uma noção de totalidade, de pertencimento ao grupo ao qual está vinculado. 
A cultura organizacional, da qual a comunicação interna é pilar inexorável, pode ser vista, portanto, como o alicerce para a formação de uma identidade dos indivíduos nas organizações, não havendo como pensar a noção de identidade senão em função da interação com outros. As identidades dos indivíduos são construídas de acordo com o ambiente em que se inserem, envolvendo, entre outras coisas, as estruturas sociais, a cultura e o histórico das relações.

Segundo José Carlos Zanelli (2003), a organização, como sistema social, inserida em seu contexto, busca preservar sua identidade e sobrevivência. Para tanto, desenvolve uma estrutura normativa (valores, normas e expectativas de papéis, padrões esperados de comportamento e interação) e uma estrutura de ação (padrões reais de interação e comportamento), originada sobretudo nas posições dirigentes. Quanto maior a identificação dos indivíduos com a organização, maior o seu comprometimento. 0 estudo da identidade de uma organização envolve, necessariamente, a atenção à sua interação com várias identidades.

A noção de identidade nas organizações se dá em função do relacionamento com outros, que é construído, mantido e modificado pelas características do contexto interativo organizacional. A comunicação interna, estrategicamente pensada, é fundamental para esse processo. Ao compartilhar objetivos, regras, valores, entre outros fatores, os indivíduos assumem comportamentos grupais moldados pela organização, motivados pela redução da incerteza de como devem sentir, agir, pensar e, ainda, de como serão vistos pelos outros.

Um claro exemplo de sucesso, no universo do futebol, de construção de uma cultura organizacional, alicerçada em um processo de comunicação interna estrategicamente planejada, é o FC Barcelona, da Espanha. Para Feran Soriano (2010), vice-presidente da agremiação entre 2003 e 2008, o Barcelona é resultado de uma filosofia baseada em valores e princípios fundamentais muito mencionados nas teorias administrativas da hoje em dia.

No caso do FC Barcelona, a cultura preserva a identidade organizacional, que se traduz na forma como os públicos, inclusive o interno, da organização a veem, a imagem que eles constroem a respeito dela. A cultura organizacional do clube espanhol busca interagir com o ambiente, adaptando-se a ele. Essa personalidade que ele adota, de ser "mais que um clube", tende a ser proativa, atenta às necessidades de mudanças, que se tornam cada vez mais presentes no ambiente organizacional. Dessa forma, a identidade do clube foi, desde a década de 1980, reconstruída para se adequar ao mercado.

\section{COMUNICAÇÃO INTERNA E PERFORMANCE ESPORTIVA: O CASO DO FC BARCELONA}

O FC Barcelona é um clube espanhol da cidade do mesmo nome, na região da Catalunha, fundado em 29 de novembro de 1899. Em 2010, uma pesquisa realizada pela empresa alemã Sport Market (2011) concluiu que a torcida do Barcelona é a maior da Europa, com cerca de 57,8 milhões de aficionados.

Com uma administração profissional, o clube planeja suas ações de forma estratégica. 0 sucesso de sua comunicação mercadológica colocou a marca FC Barcelona como uma das mais conhecidas de todo o mundo. Além do sucesso global, 0 time é fortemente identificado, localmente, com a região da Catalunha, da qual se proclamou como um dos seus símbolos. 
Esse sentimento de representação da Catalunha é reforçado por ações como expressões icônicas locais colocadas na faixa de capitão do time, que normalmente reproduz a bandeira da região, e o lema "més que un club", adotado em 1968. Atualmente, motivado pelos excelentes resultados esportivos obtidos nos últimos anos, pelas estratégicas ações mercadológicas adotadas e pela atuação da Fundación FC Barcelona ${ }^{3}$, o lema "mais que um clube" se estendeu para todo 0 mundo, colaborando para o fortalecimento da marca em escala global.

Soriano (2010) aponta como principais valores do clube: a ética, o trabalho em equipe, a inovação, a liderança e o respeito. Todos esses elementos são trabalhados de forma exaustiva por uma cultura organizacional que preconiza a valorização da identidade do clube e sua importância para a região da Catalunha. Sua cultura organizacional deve transcender, assim, os muros da agremiação, representando em suas aspirações e seus valores culturais, toda uma região importante da Espanha.

Na prática esportiva, a cultura organizacional da agremiação é construída por meio de um processo de comunicação interna, alicerçado no Centro de Formação de Atletas Oriol Tort, mais conhecido como La Nueva Masia. É lá, com toda a infraestrutura necessária para a formação do atleta e também do indivíduo, que o clube trabalha seus valores esportivos, culturais e identitários.

0 Centro de Formação de Atletas do FC Barcelona foi inaugurada em 20 de outubro de 1979, pelo então presidente do clube José Luis Nuñez, com o nome de La Masia. Localizado em um edifício próximo ao estádio Camp Nou, onde a equipe principal do clube joga suas partidas, La Masia passou a ser, a partir do início de seu funcionamento, o local de residência dos atletas que vinham de todas as partes da Espanha e, mais recentemente, com a globalização do esporte, de todo o mundo.

A residência de La Masia é utilizada para desenvolver jovens jogadores, que chegam ao clube com doze a catorze anos de idade e devem viver longe de suas famílias. No local, muita ênfase é dada, pelo clube espanhol, à formação humana e ao desenvolvimento pessoal do individuo. Como parte da formação desses futuros jogadores, o FC Barcelona também trabalha os valores de identidade do clube e a forma tática de praticar o futebol que tais atletas deverão reproduzir quando atingirem a equipe principal da agremiação.

La fórmula utilizada para la búsqueda de futuros mosqueteiros: Masia + estudios + un poco de dinero para sus gastos + gastos de viaje $=$ ingreso en el cuerpo de mosqueteros del Barça. (...) El rastreo de los nuevos mosqueteros lo realizan veinte técnicos y seis observadores, que intentan buscar en ellos el nível "Barça". (...) El principal objetivo de La Masia es intentar formar/forjar no sólo deportiva sino intelectualmente y en valores a los jóvenes que han dejado a sus famílias y sus pueblos y ciudades de procedencia para hacer carrera en el FC Barcelona (Cubeiro; Gallardo, 2011, p. 195).

0 modelo implantado pelo FC Barcelona em La Masia dá tanta importância à comunicação dos valores internos do clube que, da sua rotina diária, apenas uma hora e meia dos jovens futuros jogadores do clube é destinada à prática do futebol. A ênfase da formação do clube é dada à preparação dos adolescentes para que aqueles que fracassem no universo do futebol possam ingressar em uma universidade, em busca de uma profissão futura no mercado de trabalho. Segundo as estatísticas da própria agremiação, só $11 \%$ dos jovens chegam ao time principal do Barcelona. Aproximadamente 40\% se dedicam ao futebol profissional em outros clubes e o restante deixa o esporte (Cubeiro; Gallardo, 2011, p. 199).

3 A atuação da Fundación FC Barcelona está baseada nas seguintes premissas: utilização do esporte como eixo de atuação; o fomento da educação e dos valores positivos do esporte; a infância e a juventude como objetivos beneficiários; e a projeção da Catalunha por meio do Barça. Desde a sua constituição, em 1994, a fundação tem sido uma fonte inesgotável de participação cidadã para as inúmeras atividades sociais, culturais e desportivas que o clube promove. Com base na experiência adquirida no campo do esporte e dos seus valores, ela propõe um programa de atuação com foco na transmissão, às crianças e aos adolescentes, dos valores positivos, tomando a prática esportiva como meio para promover seu crescimento sadio e harmônico. 
A preparação técnica e tática dos atletas também é trabalhada desde a adolescência. 0 treinador brasileiro Renê Simões, no prefácio do livro Todos os segredos do melhor time do mundo, de Sandro Modeo (2012), aponta que

\begin{abstract}
o Barcelona não é só um time, é mais que um clube (...). Nunca admitiu que um treinador fosse maior que o clube e que um jogador fosse maior que o modelo de jogo. Essas explicações de modelo de jogo farão com que todos entendam que o que acontece com o Barcelona atual não é obra do acaso, ao juntar um grupo de excelentes jogadores. (...) 0 clube e 0 time são frutos de um plano montado há mais de duas décadas e que até hoje é aprimorado com a criação de La Masia. (...) Estive lá e pude constatar, ao ver os jovens treinando e jogando, que, ao assistir qualquer categoria treinar ou jogar, eu via o Barcelona e não apenas Messi, Puyol, Iniesta, Daniel Alves e outros. 0 modelo estava fixado e os conceitos firmados na execução do pensamento coletivo (Simões, 2012, p.viii-ix).
\end{abstract}

Os grandes ídolos atuais do FC Barcelona, como o argentino Lionel Messi e o espanhol Andrés Iniesta, são astros do futebol que primam pelo senso de coletividade e trabalho em equipe, assimilados desde os tempos em que viviam em La Masia. Além disso, estão plenamente identificados com os valores do clube, como o respeito ao adversário e aos torcedores e a ética na prática esportiva.

O clube espanhol, mais do que uma identidade tática de seus atletas, tem uma identidade cultural, com princípios e valores regiamente definidos. Todos esses valores podem ser exemplificados pelo fato ocorrido no final da temporada 2011-2012 da Liga Espanhola, amplamente noticiado pela imprensa brasileira.

\begin{abstract}
Se no Brasil são comuns as dancinhas na hora de comemorar gols, o mesmo não se pode dizer do Barcelona. No domingo, 0 brasileiro Daniel Alves foi repreendido pelo zagueiro Puyol e pelo técnico Pep Guardiola após celebrar desta forma um gol na goleada por 7 a 0 sobre o Rayo Vallecano. 0 lance aconteceu quando o Barça marcou seu quinto tento na partida. Daniel Alves cruzou para Thiago Alcântara, filho do tetracampeão Mazinho, fazer. Na hora de comemorar, os dois fizeram a coreografia da música "Eu quero tchu, eu quero tchá", que ficou famosa graças ao santista Neymar. Descontente com a celebração, o capitão Puyol tratou de acabar com a brincadeira e puxou seus companheiros de volta a seu campo. Mais tarde, na entrevista coletiva, Guardiola lamentou o ocorrido. "Pedimos desculpas aos torcedores do Rayo pela celebração de Thiago e Dani Alves. É uma atitude que não voltará a acontecer e não é própria de jogadores do Barcelona", disparou o treinador. Depois da bronca, coube a Daniel Alves se redimir publicamente, mas não sem também se mostrar contrariado. "Quero pedir perdão aos torcedores do Rayo que se sentiram ofendidos com a dança. Em nenhum momento quis ofender ninguém, somente me sentir bem", falou o brasileiro. "Me disseram uma vez quando criança que o futebol era para se divertir" (Bol Notícias, 2012).
\end{abstract}

Mais do que a postura perante o gol, sobressai uma postura perante a vida, uma filosofia cultural de respeito ao adversário. Acostumado aos valores culturais do Brasil, onde "o futebol é para se divertir", Daniel Alves foi obrigado a pedir desculpas aos torcedores adversários por romper com os padrões culturais e institucionais que identificam o FC Barcelona, entre eles o respeito ao jogo e ao adversário. Tanto que, simbolicamente, sua atitude foi repreendida de forma veemente pelas duas maiores lideranças da agremiação, seu então treinador (Pep Guardiola) e seu capitão (Charles Puyol)4.

A comunicação interna apresenta, assim, intensa participação na construção da cultura organizacional da multinacional equipe do FC Barcelona. 0 sucesso desse processo é tão grande que o ex-jogador holandês Ronald Koeman, que foi o capitão do time do FC Barcelona campeão europeu de 1992 e hoje é treinador de futebol, afirmou:

Este equipo tiene una virtud que no se ve pero que es acojonante. La humildad. No es ninguna tontería que doce chicos que hoy están en la plantilla sean de la cantera. Hoy el vestuario del Barça está unido alrededor de una filosofía, de una cultura, que han mamado desde niños. En mi época, los líderes eran un holandés, un búlgaro, un brasileño, un danés, un vasco... Hoy todos comparten el mismo idioma y la misma cultura. Y eso se nota. Están unidos como jamás lo habíamos estado (Koeman, apud Cubeiro e Gallardo, 2011, p. 190).

4 Ambos, Pep Guardiola e Charles Pujol, formados em La Masia, o Centro de Formação de Atletas do FC Barcelona. 
A cultura construída pelo FC Barcelona se sobrepõe, na pós-modernidade, à cultura adquirida, por exemplo, por Daniel Alves, em sua formação na infância e adolescência no Brasil. A cultura e os valores do clube não são, portanto, uma coisa em si, mas um processo interminável. 0 FC Barcelona é gerenciado assim: se difunde perante todo o mundo, espalhando sua identidade e mostrando sua cultura. A agremiação consegue ser diferente, original e autêntica, aumentando o valor de sua marca para todos os seus stakeholders. A comunicação interna é vital para o sucesso dessa estratégia, seja do ponto de vista econômico-financeiro, seja do ponto de vista da performance esportiva.

\section{CONSIDERAÇÕES FINAIS}

0 desenvolvimento do esporte enquanto elemento de comunicação e marketing e o crescimento da indústria do entretenimento e consumo colocaram o fenômeno esportivo no centro do processo de criação de valor para empresas, marcas e produtos.

Pelo seu caráter muitas vezes intangível, pelos atributos positivos que podem, em geral, a ele ser associados, o esporte apresenta, em sua plenitude, uma série de possibilidades para edificação de uma marca forte e da criação de valor para seus stakeholders. Seja em seus aspectos mais sociais - ligados à participação e à educação -, seja em seus aspectos de mercado - voltados ao desempenho e à performance -, o esporte auxilia na construção das marcas "nos corações e nas mentes" dos consumidores de produtos e serviços oferecidos ao mercado pelas organizações.

0 entendimento de que uma marca forte é, hoje, ativo financeiro de uma organização, dá ao esporte uma importância estratégica. Atletas, clubes e modalidades esportivas passam a contribuir, assim, de forma cada vez mais preponderante, para o sucesso de uma empresa. 0 papel da cultura organizacional cresce em importância dentro desse universo. A construção da identidade de uma agremiação passa a ser uma das estratégias de comunicação para os agentes esportivos e para os gestores do esporte.

A cultura construída, quando bem edificada, permite à agremiação, por meio do desenvolvimento de uma identidade clara, com valores bem definidos e atitudes que agregam valor aos seus grupos de interesse, contribuir para o equilíbrio entre 0 sucesso esportivo e os excelentes resultados econômicos e financeiros. A comunicação interna exerce papel preponderante na edificação dessa cultura.

0 presente trabalho fornece as bases teóricas e conceituais que permitem o entendimento da comunicação interna na transformação da cultura adquirida, oriunda das identidades nacionais, para construir uma cultura moldada por gestores que, em sua atividade, procuram fazer coincidir os objetivos individuais dos atletas, de diferentes origens, com o objetivo comum do clube, da agremiação. 0 FC Barcelona é um notável exemplo do sucesso desse processo.

\section{REFERÊNCIAS}

BOL NOTÍCIAS. Daniel Alves comemora gol com dança, é repreendido e pede desculpas. Disponível em: <http://noticias.bol. uol.com.br/esporte/2012/04/30/daniel-alves-comemora-gol-com-danca-e-repreendido-e-pede-desculpas-assista.jhtm>. Acesso em 30 abr. 2012. 
CUBEIRO, Juan Carlos; GALLARDO, Leonor. Los mosqueteros de Guardiola: claves prácticas del mejor equipo de la historia y cómo incorporarlas e tu proprio equipo profesional. Barcelona: Alienta, 2012.

DUPUIS, Jean-Pierre. Antropologia, cultura e organizações: proposta de um modelo construtivista. In: CHANLAT, JeanFrançois (Org). O indivíduo na organização: dimensões esquecidas. Vol. III. São Paulo: Atlas, 1996.

ELIOT, Thomas Stearns. Notas para uma definição de cultura. São Paulo: Perspectiva, 1988.

GARCÍA-CANCLINI, Néstor. Consumidores e cidadãos: conflitos multiculturais de globalização. Trad. de Maurício Santana Dias. 4. ed. Rio de Janeiro: UFRJ, 2001.

GIULIANOTTI, Richard. Sociologia do futebol: dimensões históricas e socioculturais do esporte das multidões. São Paulo: Nova Alexandria, 1999.

KUNSCH, Margarida M. Krohling. Planejamento de relações públicas na comunicação integrada. 4. ed. - rev. e ampl. São Paulo: Summus, 2003.

MODEO, Sandro. Todos os segredos do melhor time do mundo. Rio de Janeiro: Qualitymark, 2012.

MORGAN, Melissa Johnson; SUMMERS, Jane. Marketing esportivo. São Paulo: Thomson, 2006.

SIMÕES, Renê. Prefácio à edição brasileira. In: MODEO, Sandro. Todos os segredos do melhor time do mundo. Rio de Janeiro: Qualitymark, 2012.

SORIANO, Ferran. A bola não entra por acaso: estratégias inovadoras de gestão inspiradas no mundo do futebol. São Paulo: Larousse, 2010.

SPORT MARKET. Barcelona é único clube da Europa com mais torcedores que o Flamengo. (Em português). Disponível em: <http:www.thesportmarket.blz>. Acesso em: 09 jan. 2011.

ZANELLI, José Carlos. Interação humana e gestão: uma compreensão introdutória da construção organizacional. Rio de Janeiro: LAB, 2003.

Artigo recebido em 20.08.2013 e aceito em 20.12.2013. 